\title{
Software engineering based fault tolerance model for information system in plants shopping center
}

\author{
Saja Nasir ${ }^{1}$, Muayad Croock ${ }^{2}$, Salih Al-Qaraawi ${ }^{3}$ \\ ${ }^{1}$ Institute of Informatics for Postgraduate Studies, Iraqi Commission for Computers and Informatics, Iraq \\ ${ }^{2}$ Computer Engineering Department, University of Technology, Iraq \\ ${ }^{3}$ Control and Systems Engineering Department, University of Technology, Iraq
}

\begin{tabular}{l} 
Article Info \\
\hline Article history: \\
Received Mar 23, 2020 \\
Revised May 17, 2020 \\
Accepted Jun 19, 2020 \\
\hline
\end{tabular}

\section{Keywords:}

Fault tolerance

Information system

Mobile application

QR code

Web application

\begin{abstract}
The rapid development of mobile phone technologies in recent years promoted them for being used in various areas of life, such as commercial, health, transportation and tourism and other uses. In this paper, a software engineering based fault tolerance model is proposed to manage the expected faults in the adopted servers. The underlying QR based information system in plants shopping center employs different local serves allocated at local shops that are connected to the main server. In a fault case detection at any local server, the main server can cover the management of the system until the maintenance is completed. This is performed in efficient way as the main server keeps a copy of the information for all local branches. It is important to note that the self-checking process is adopted for fault detection. After completing the maintenance, a copy of the updated information is sent back to the investigated local server including all sales, etc. Moreover, the main and local servers contain information about all offer's plants in different languages and in text and image form, customer's information and admin's information. The proposed system is tested in several cases to prove the efficiency and effectivity in retrieving and managing information and data as well as the fault tolerance administration.
\end{abstract}

Copyright $(2020$ Institute of Advanced Engineering and Science. All rights reserved.

\section{Corresponding Author:}

Saja Naser Selman,

Institute of Informatics for Postgraduate Studies,

Iraqi Commission for Computers and Informatics, Iraq.

Email: sajanaser.sn@gmail.com ${ }^{1}$, Muayad.S.Croock@uotechnology.edu.iq ${ }^{2}$

\section{INTRODUCTION}

Nowadays, the explosive growth of the development of mobile phone applications has made the issue of life easier. Some institutions such as museums, commercials enterprises or health have a large number of visitors and they may not have time to wait for the human guide to getting knowledge about the offered item $[1,2]$. Such a large number of visitors needs management and organize to the movement and requirement, in addition to that, each visitor may need information about offered objects in the shop. All of these requirements need to efficient and qualified guidance [3-5]. Thus, there is a need to develop a mobile application to works as an e-guide to introduce complete information to each visitor in the shop and at any time without waste time or cause disturbance to the visitor. These systems work to improve the performance and services introduced to the customer, in order to provide comfort to them during shopping. This lead to an increase in the number of visitors, so increasing the profit to the shop [6]. The integrated systems are designing for fault tolerance in general, so the system becomes able to deal with failure (fault) even if during execution to prevent stopping the system entirely. Mirror many of the fault tolerance systems are all its operations. This means that each operation must be executed on a duplicated system twice or more. The reason for that is in case of fault occur, the other parts of the system work as an alternative. The system is fault-tolerant if it is linked to dependable systems. In fault-tolerance systems, 
dependability covers part of the useful requirements. An example of these requirements are: reliability, safety, ease of maintenance and availability [7,8].

In this paper QR code technology is used to retrieve information about the offered item. All information is stored in the local server and backup at the main server. The main server works instead of the local server when a fault occurs in the local server, such as overload on the server which makes it is busy for a long time or may have another error. Fault is found using self-checking process based on software engineering technique. In this case, the work is converted to the main server in a transparent manner for the visitor to complete the system work without stop.

\section{RELATED WORKS}

This section details the related work about mobile applications that focused on information systems that use the QR code and the fault-tolerant systems. In [9, 10], the authors introduced smart guide systems to the mobile visitor's phone, that can be used in several enterprises such as commercial, health and education institutions. These applications worked to retrieve full information about all offered items without calling the human to get help. The retrieve information was taken two formats: text and sound. These applications supported several languages which suitable for many nationalities. If this application was executed in shopping such as a mall, a virtual shopping cart is provided to help the visitor in movement inside the mall. Moreover, when the visitor decides to buy items, he can use a bank account to pay the cost. In [11], the authors introduced an indoor localization system, which was used to improve the visitor's experience at the museum. The proposed system depended on the Bluetooth low energy beacons proximity and localization capabilities to automatically provide the visitors with cultural content. In addition, the location of the visitor at the museum was estimated based on the RSS technology. This system was designed to be easy to extend to the Internet of Things technology and its effectiveness has been evaluated through experience. In [12], the authors introduced an android mobile application used by visitors of the museum to recognize the article which views information in an image, text, video or audio format via reading $\mathrm{QR}$ code that nearby the statue. This application was used to enhance the abilities of the visitors in the museum to access information by scan the QR tag from their smart mobile phone. It provided guidance tasks in the museum instead of a human guide. In [13], the authors proposed an android mobile application for object identification relies on scan QR code. This system was designed for identification many of items that exist by the easiest method. The proposed system consists of a database, web services used as intermediate to access the database and mobile application for the user to run it is on his/her mobile smartphone or tablet computers.

In $[14,15]$, the authors introduced a survey on fault tolerance. Each system was able to interactive safely with unexpected failures or faults from hardware or software called fault tolerance. The faults must be assessed and handled in an effective way, for achieving dependability and robustness in cloud computing. The authors proposed an algorithm using artificial neural network (ANN) in order to detect the faults which overcome the algorithms' gaps and provide a model of fault tolerance. In [16], the authors introduced a survey about various fault-tolerance mechanisms in the distributed systems, that used to prevent multiple failures of the system and in different points of failure through high redundancy, considering replication and distributed services availability. In [17], the authors presented two techniques for providing a system of fault-tolerance. The first technique used redundancy in the infrastructure of the network. The second, adaptive technology is proposed. In the second technique, adaptive components such as H.264 codec and (H.265) were achieved to guarantee better performance.

\section{PROPOSED SYSTEM STRUCTURE}

The proposed QR based information system for plants shopping center with information management contains five important parts from as follow:

- QR code tags: it is a two-dimensional form barcode, which can encode the large amount and different types of data [18]. Easiest way to access information that embedded on QR code Quickly by installed QR scanner application on smart mobile phones [19]. To generate QR code, we can visit one of the web sites that available online and download the code as a jpg image file and label on each offered item [20, 21].

- Mobile Application: to design a mobile application to this work, the Android Studio IDE (Integrated Development environment) 3.4.1 software is used [22]. This application is developed to the visitor's mobile phone in order to decode the QR code, send a request to the server, receiving information in image and text format from the server and display information on the mobile phone screen of the visitor. In addition to that, buying items by using a bank account and other uses.

- Local Server (LA): in this work, the local server is provided with AppServ software to store the information of the entire system, where this server is installed to sub-station and then linked to 
the main server. The AppServ contains a package of software such (Apache, PHP, MySQL, phpMyAdmin) [23]. The records stored on this server can be accessed by the system administrator for several purposes such as updating the system data from adding, deleting or updating the item CRUD.

- Main Server (MS): the main server is adopted with AppServ software. This server saves information of all stations that Affiliated to the same enterprise. It is employed as a cloud to store data for all stations, where works as a backup if the data in the local server has an error or to inform the visitor about what stations that provide the desired items through the search process.

- Access Point: the TP-LINK router was used as an access point to connect clients' devices with the local or main server. In order to send the requests and receive the response to and from the server. The access point in this proposed system is very necessary to provide a large coverage area of Wi-Fi network.

All of these elements the hardware and software linked with each other in order to works the proposed system in the correct manner. Figure 1 shows the structure of the proposed system, while Figure 2 represents the block diagram that explains the functions of the proposed system for the plants' shopping center.

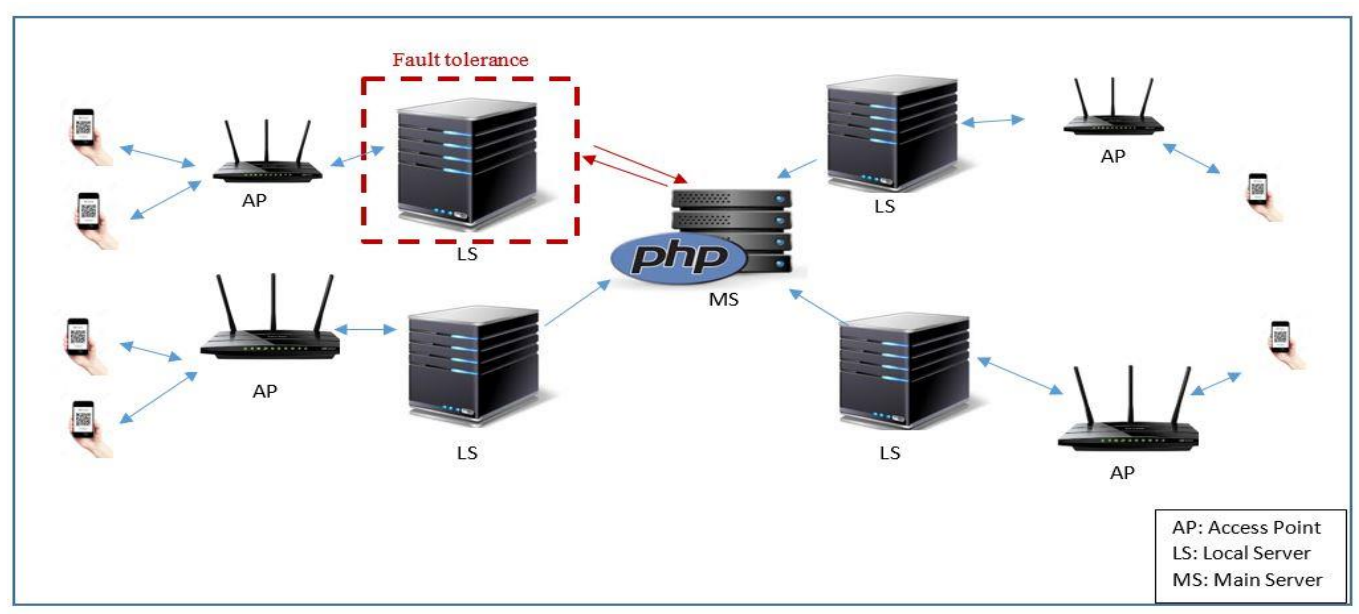

Figure 1. Proposed system structure

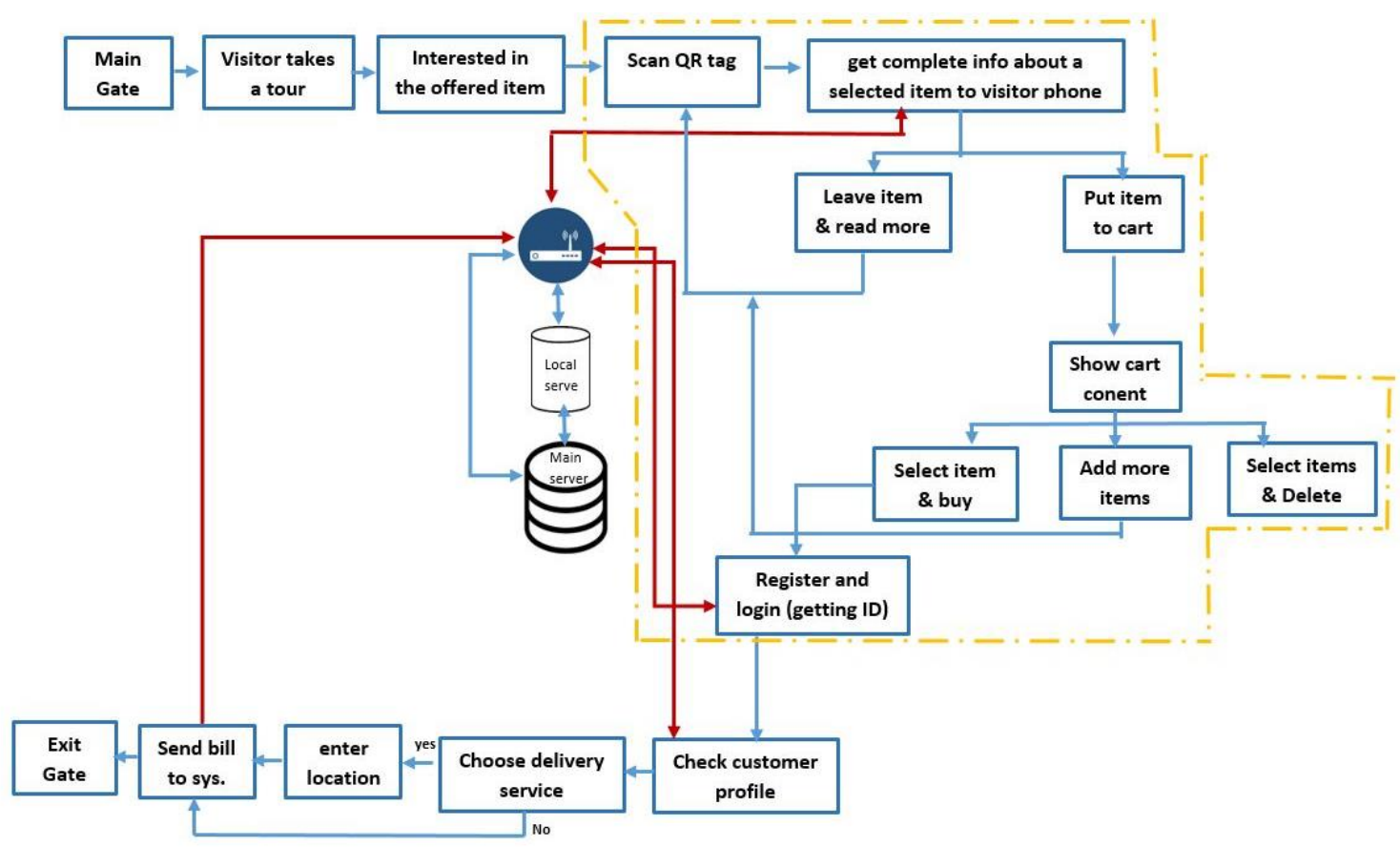

Figure 2. Proposed system block diagram of pants shopping center 


\section{PROPOSED FAULT TOLERANCE BASED ALGORTHIMS}

To implement the proposed system, different algorithms were proposed to running the system correctly without stopping. These algorithms are explained in full detail as a follows:

\subsection{Proposed management algorithm}

The webpages are used to administrating all data of the proposed system by administrator of system. PHP programming language that includes in the AppServ package is utilized to develop these pages. Figure 3 illustrates the flowchart for administrating algorithm of the plant's system.

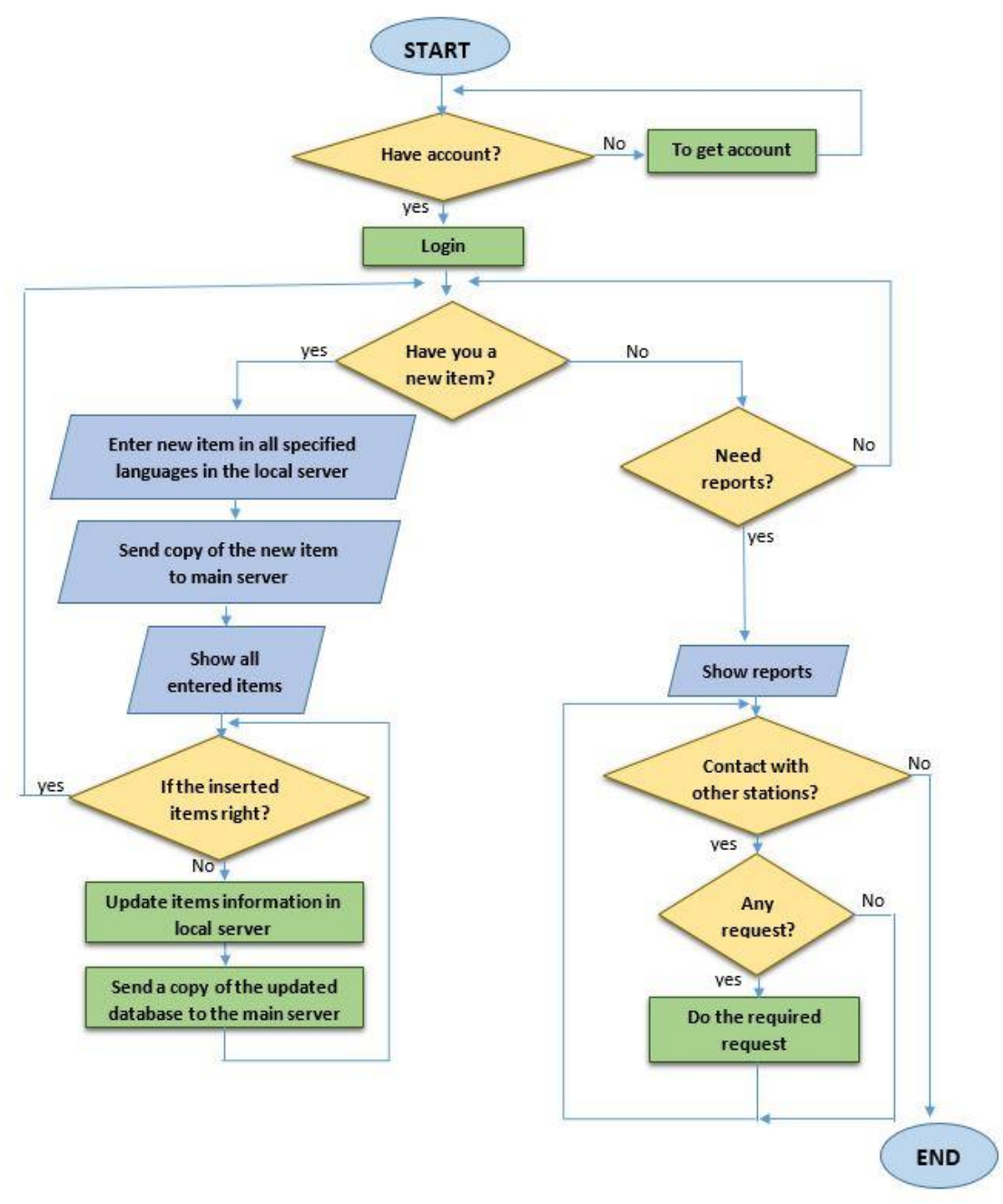

Figure 3. Flowchart of the proposed system admin activities

The administrator (admin) of the system must have an account to login to the system. Otherwise, the main admin can add a new admin to the system. After the admin login to the system, he/she can make an update to the system's database, such as enter new items, show items, update items or delete items. In addition to that, the admin can show reports about the movement of visitors in the sub-station, and also can contact with an admin from another sub-station. When he needs to request additional items from outside the station, providing another station with new items that may be redundant at the station or any other matter, the admin can call other admin and manage any matter.

Figure 4 illustrates how the fault tolerance works in the local server and main server. The Local server makes a self-checking to its working. If it works correctly, a copy of the updated data is sent to the main server for saving a backup from the updated data continuously. But, if the local server has some faults, the work is converted to the main server. When the local server returns to the work after a time period, the backup of data is sent from the main server to the local server to prevent conflict in data between two servers. 


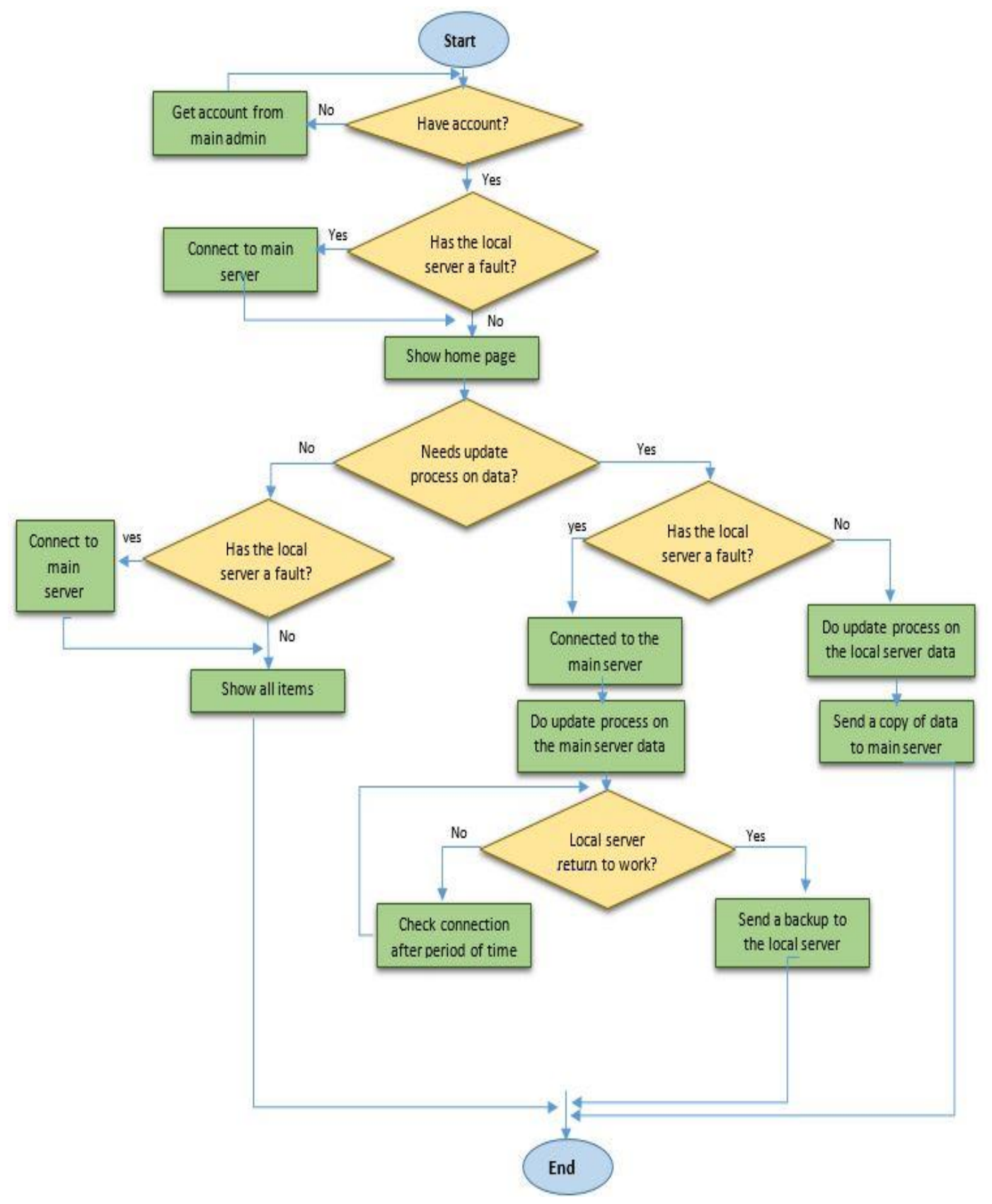

Figure 4. Flowchart of the proposed system admin's activities with fault tolerance

\subsection{Proposed mobile application algorithm}

When the visitor enters the plants' shopping center and needs to know information about the offered item, they must install the application of plants provided by the company to its customers. When the QR code scan by the visitor, the information is retrieved from the local server if it works without any fault. Otherwise, if the local server has a fault, the work is converted to the main server immediately to prevent the system from stopping. If the visitor decides to buy items and the local server working correctly, he must register in the local server and getting an account, in addition to record purchased items also in the local server, after that, the local server sends a copy of the recorded data to the main server as backup. But if the local server has a fault, also the work is converted to the main server and after the local server return to the work, and the backup is sent from the main server to the local to prevent the conflict in data between the servers and maintain consistency between them. Figure 5 illustrates the fault tolerance with for mobile application of visitor between the local and main server. 


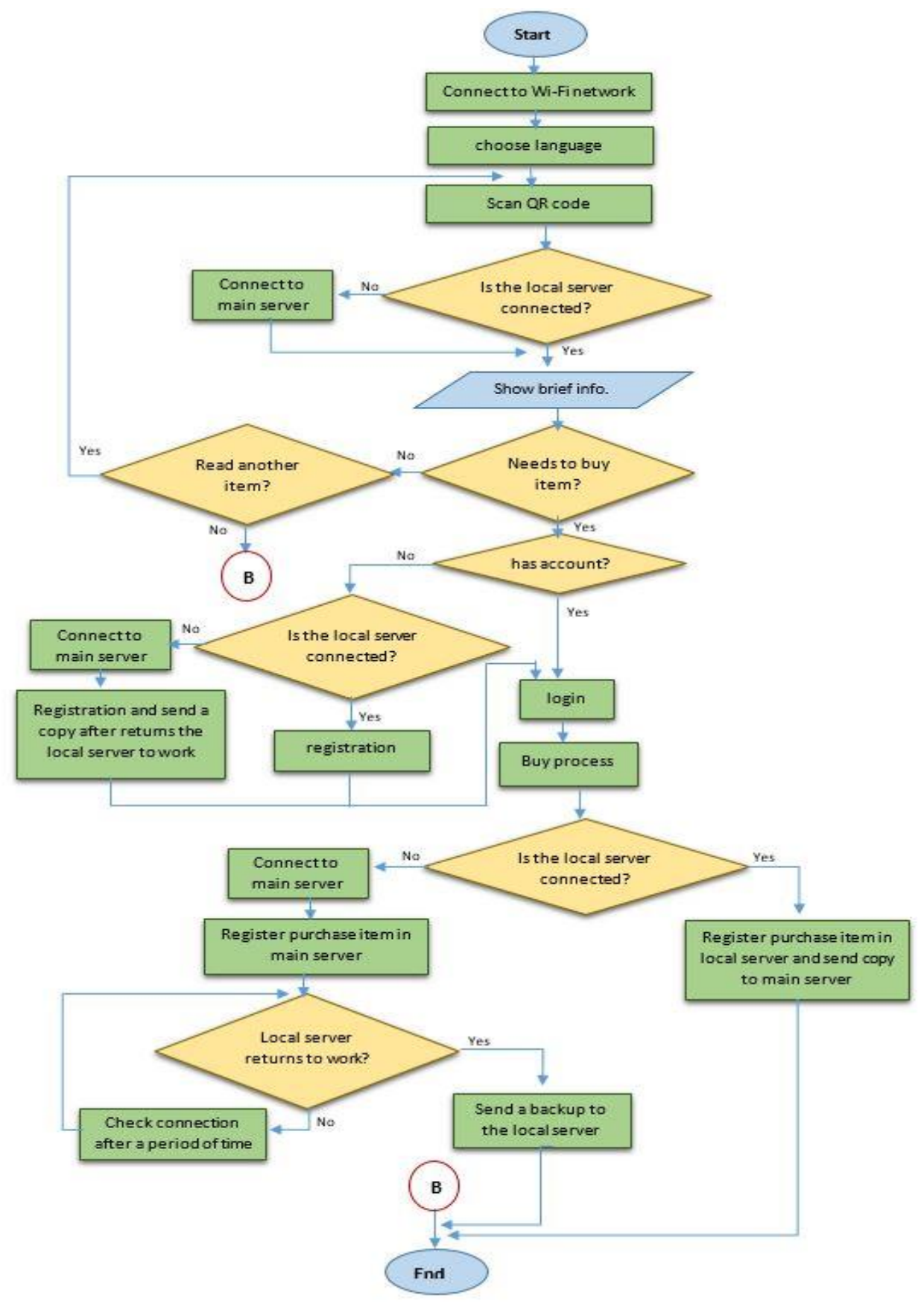

Figure 5. Flowchart of the proposed system mobile application with fault tolerance

\section{RESULTS AND DISCUSSION}

For testing the proposed system, a simple prototype is adopted to present the idea behind this paper. The prototype contains different components from hardware and software. Hardware Components: one TP-LINK router as an access point, HP laptop a main server work as a cloud to all stations, Dell laptop works as a local server to sub-station and smartphone Galaxy S8 as the client's device. Software Components: AppServ package for programing that include (MySql, PHP and Apache), Android Studio platform 3.4.1 version with many of libraries so that the implementation in Gridle file for example (Volley:1.1.1, picasso.2.5.2, etc.) $[24,25]$.

When the local server is working properly, a message appears on the admin's screen for inform that the local server is connected as shown in Figure 6. But if a malfunction or fault of the local server occurs suddenly, a message is appeared that the admin's screen to provide the system with information that the work is converted to the main server temporarily and the maintenance team was called to fix the problem as shown 
in Figure 7. When a problem occurred in the local server, the work is converting to the main server according to the proposed algorithms of the system. The applying of fault tolerance technique temprarly uses the main server for overcoming the detetced fault. When the connection to the local server is return correctly, the main server automatically sends a backup of the updated data to the local server to prevent the conflict between the data. Figure 8 views the message to the admin include the local server returns to the work correctly.

To test the failure case in the local server of the proposed system when the visitor uses the plant's application, the fault injection was used to test the proper fault tolerance working and how the work is converted from the local server to the main server. When the visitor scans a QR tag and not found an error in the local server, the visitor's mobile phone is linked to the local server and a message appears to the admin of the sub-station about local server status on the home page of the plants system as shown in Figure 9. In another case, if the local server has an error, the visitor's mobile phone linked to the main server automatically over the adopted Internet. A message is appeared at the system's home page to inform the admin of the sub-station about the fault in the local server as shown in Figure 10. After a period of time, if the local server returns to the work, the main server sends a backup of updated data to the local server.
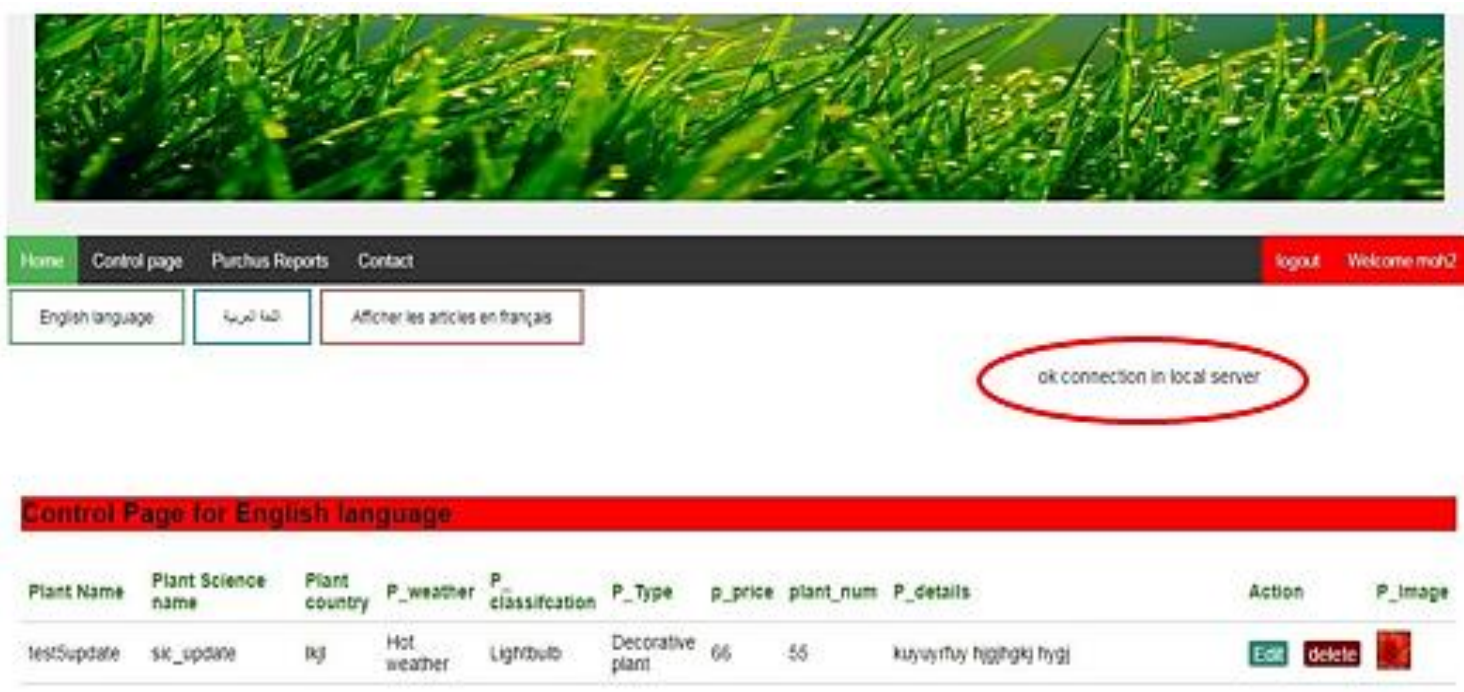

Figure 6. Message to the admin about the local server connecting
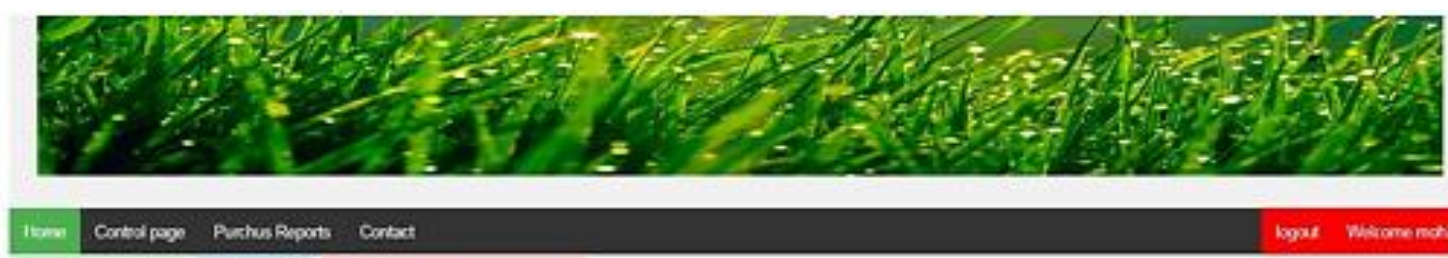

\begin{tabular}{|c|c|c|}
\hline Evith ungaph & 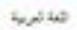 & Aecter in xitcien on farcan \\
\hline
\end{tabular}

Fast in lecceserver ans coeven so man sever
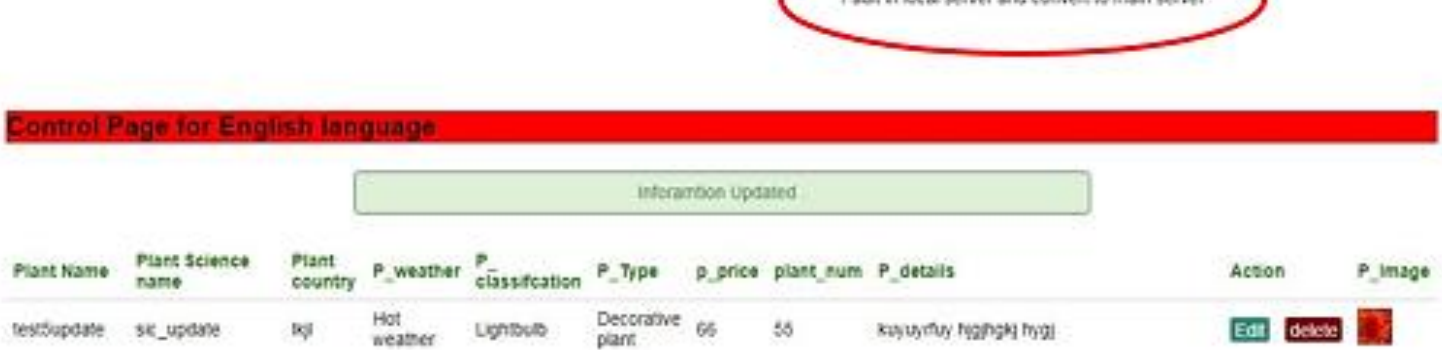

Figure 7. Message to the admin about a fault occurred in connecting with the local server 


\begin{tabular}{|c|c|c|c|}
\hline Hame & Control pays & Purchus forpots & Contaxt \\
\hline \multicolumn{2}{|c|}{ Englash unqage } & قان لريط & Afcher les atcies en trancas \\
\hline
\end{tabular}

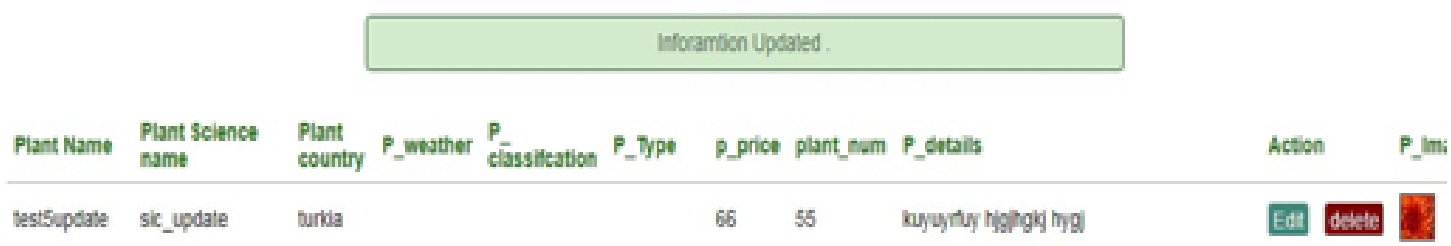

Figure 8. Message to the admin about correct the fault that occurred in the local server

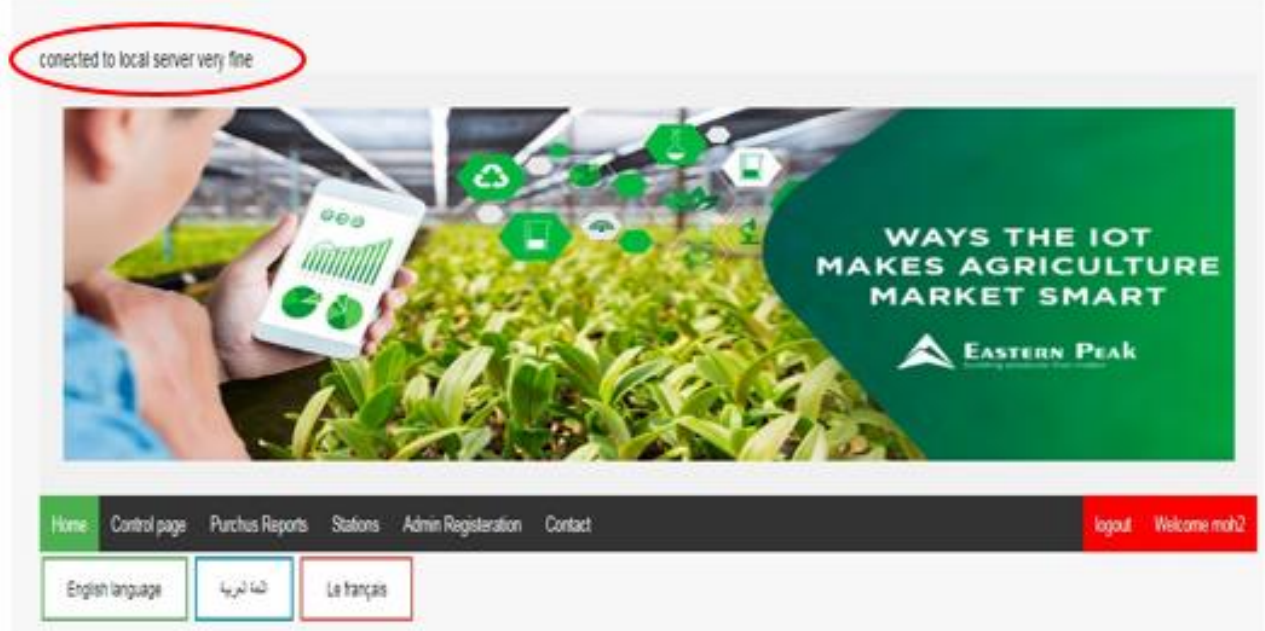

Figure 9. Message to inform the admin about the client's mobile phone linked to the local server

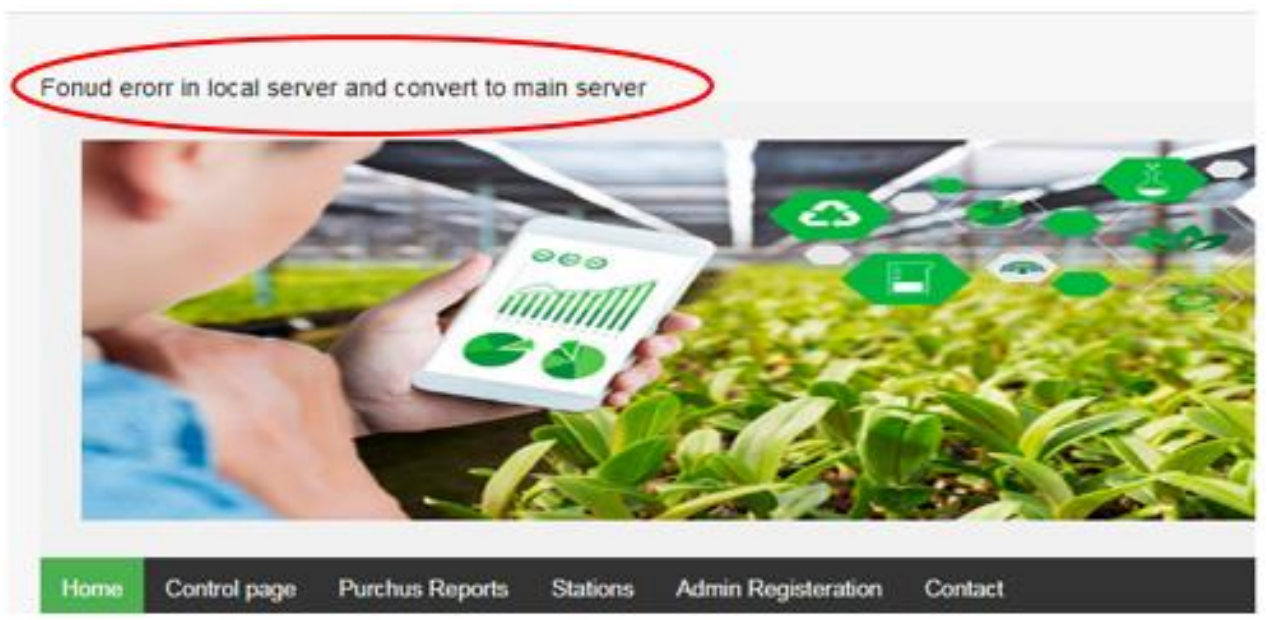

Figure 10. The message to inform the admin about linked the client's mobile phone to the main 


\section{CONCLUSION}

A software engineering fault tolerance model for QR based information system for plants shopping center was proposed. Different algorithms were presented to cover the aim of the proposed system. These algorithms managed the software mobile applica tion and the information retrieving in addition to the network hardware management. In case of fault occurrence in the local server at a shop, the main server took the step of managing the local shop till the fault is fixed. The fault is detected using self-checking process as a part of software engineering techniques. When the fault is fixed, the local server took its order in managing the local shop and the updated information is copied from the main server. The proposed system was tested over different case studies and the results were proved the efficiency in terms of fault tolerance applying.

\section{REFERENCES}

[1] C. Dastoli, P. Bolzan, M. Bianchini, and B. Del Curto, "Mobile AR Tourist Attraction Guide System Design Based on Image Recognition and User Behavior," International Conference on Intelligent Human Systems Integration, vol. 2, pp. 833-839, 2019.

[2] J. F. Ibanez, J. E. S. Castaneda, and J. C. M. Santos, "An IoT Camera System for the Collection of Data Using QR Code as Object Recognition Algorithm," Congr. Int. Innov. y Tendencias en Ing. CONIITI 2018 - Proc., pp. 1-6, 2018.

[3] H. H. Owaied, H. A. Farhan, N. Al-Hawamdeh, and N. Al-Okialy, "A model for intelligent tourism guide system," Journal of Applied Sciences, vol. 11, no. 2. pp. 342-347, 2011.

[4] O. Al Hammadi, A. Al Hebsi, M. J. Zemerly, and J. W. P. Ng, "Indoor localization and guidance using portable smartphones," Proc. IEEE/WIC/ACM Int. Conf. Web Intell. Intell. Agent Technol. Work, vol. 3, pp. 337-341, 2012.

[5] D. Gavalas, C. Konstantopoulos, K. Mastakas, and G. Pantziou, "Mobile recommender systems in tourism," J. Netw. Comput. Appl., vol. 39, no. 1, pp. 319-333, 2014.

[6] D. Parra, R. Verdugo, G. García-galleguillos, and M. Nussbaum, "Using QR codes to increase user engagement in museum-like spaces," Comput. Human Behav., vol. 60, pp. 73-85, 2016.

[7] G. O. Regan and I. Mackie, "Undergraduate Topics in Computer Science," Concise Guide to Software Engineering Series editor, 2017.

[8] M. Liotine, "Network Reliability and Fault Tolerance," Handb. Comput. Networks, vol. 3, pp. 372-383, 2012.

[9] B. Ahmed and S. Al-Qaraawi, "Design and Implementation Guidance Mobile Application 1 1,2," Int. J. of Advanced Res. Comput. Eng. Technol., vol. 8, no. 7, pp. 283-290, 2019.

[10] B. Ahmed and S. Al-qaraawi, "Design and Implementation of e-Shopping System Using QR Code and Smart Mobile Phone," Iraqi J. Comput. Commun. Control Syst. Eng., vol. 19, no. 3, pp. 56-64, 2019.

[11] P. Spachos and K. N. Plataniotis, "BLE Beacons for Indoor Positioning at an Interactive IoT-Based Smart Museum," arXiv Prepr. arXiv2001.07686, pp. 1-11, 2020.

[12] S. Patil, M. S. Limbekar, M. A. Mane, and M. N. Potnis, "Smart Guide-an approach to the Smart Museum using Android," Int. Res. J. Eng. Technol., vol. 5, no. 2, 2018.

[13] D. Jagodi, D. Vuji, and S. Ran, "Android system for identification of objects based on QR code," Telecommun. Forum Telfor, vol. 7, pp. 922-925, 2015.

[14] Z. Amin, H. Singh, and N. Sethi, "Review on Fault Tolerance Techniques in Cloud Computing," Int. J. Comput. Appl., vol. 116, no. 18, pp. 11-17, 2015.

[15] S. M. Hosseini and M. G. Arani, "Fault-Tolerance Techniques in Cloud Storage: A Survey," Int. J. Database Theory Appl., vol. 8, no. 4, pp. 183-190, 2015.

[16] A. Sari and M. Akkaya, "Fault Tolerance Mechanisms in Distributed Systems," Int. J. Commun. Netw. Syst. Sci., vol. 08, no. 12, pp. 471-482, 2015.

[17] M. Monica O, M. Sanusi, and A. Adamu Y, "Fault -Tolerance Techniques for an Enterprise Network," Int. J. Adv. Sci. Res. Eng., vol. 05, no. 11, pp. 58-66, 2019.

[18] S. Tiwari, "An introduction to QR code technology," Proc. 15th Int. Conf. Inf. Technol. vol. 1, pp. 39-44, 2017.

[19] K. Zorenko, Yaroslav and Kosenko, "Technology of QR code creation for interactive book," 2018.

[20] S. S. Kulkarni and C. Malagi, "Creation and Analysis of QR Code," Bonfring Int. J. Softw. Eng. Soft Comput., vol. 6, no. Special Issue, pp. 86-89, 2016.

[21] “Gerador de código QR - Crie aqui códigos QR gratuitos," [Online], Available: https://br.qr-code-generator.com.

[22] "Download Android Studio and SDK tools|Android Developers," [Online], Available: https://developer.android.com/studio.

[23] "AppServ: Apache + PHP + MYSQL - AppServ, AppServHosting, AppServNetwork, AppServ Download," [Online], Available: https://www.appserv.org/en/.

[24] "Volley overview | Android Developers." [Online], Available: https://developer.android.com/training/volley.

[25] “Picasso." [Online]. Available: https://square.github.io/picasso/. [Accessed: 12-Jan-2020]. 